\title{
Pengukuran Kualitas Pelayanan dan Kepuasan Pelanggan Terhadap Loyalitas Pelanggan pada Industri Logistik
}

\author{
Aditia Sovia Pramudita \\ Program Studi Logistik Bisnis, Politeknik Pos Indonesia \\ email: aditiasovia@poltekpos.ac.id
}

\begin{abstract}
ABSTRAK
PT XYZ Logistics adalah perusahaan yang bergerak dalam pengiriman barang. Dalam layanannya, perusahaan mengalami berbagai keluhan yang dapat mempengaruhi kepuasan pelanggan yang berdampak pada loyalitas pelanggan. Penelitian ini bertujuan untuk mengetahui bagaimana pengaruh kualitas dan kepuasan layanan terhadap loyalitas pelanggan. Metode yang digunakan dalam penelitian ini adalah analisis regresi logistik ordinal. Hasil penelitian menunjukkan bahwa variabel yang berpengaruh signifikan terhadap loyalitas pelanggan adalah kualitas layanan pada indikator memberikan informasi/ penjelasan kepada masing-masing pelanggan. Sedangkan variabel kepuasan pelanggan tidak berpengaruh terhadap loyalitas pelanggan. Upaya yang dapat dilakukan oleh PT XYZ Logistics dalam menjaga loyalitas pelanggan termasuk menciptakan informasi karyawan dan sistem pelatihan.
\end{abstract}

Kata Kunci: kualitas layanan, kepuasan pelanggan, loyalitas pelanggan, regresi logistik ordinal, provider logistik

\section{PENDAHULUAN}

Perkembangan dunia logistik di Indonesia berkembang dengan pesat, ini ditunjukan dengan adanya peningkatan kondisi pasar yang diukur dari Compound Annual Growth Rate (CAGR) atau disebut sebagai laju pertumbuhan majemuk tahunan. Pertumbuhan industri logistik pada 2013 2017 sebesar $11,7 \%$. Pertumbuhan tersebut didukung oleh pertumbuhan freight forwarding yang mencapai mencapai 11,8 $\%$ dan pertumbuhan express \& small parcel mencapai 21,7 \% (Berita Satu, 2017).

Pertumbuhan tersebut didukung dengan adanya pertumbuhan ICT di dunia khususnya di Indonesia yang membuat peta pertumbuhan industri menjadi berubah (Pramudita, Yanuar, \& Hilman, 2019). Hal ini menjadikan volatilitas Indonesia tertinggi se-ASEAN. Kondisi tersebut menimbulkan munculnya perusahaan perusahaan baru yang membuat persaingan menjadi semakin ketat. Perusahaan yang bergerak dibidang logistik tidak terlepas dari peran customer. Customer terbagi menjadi beberapa segmen pasar, tetapi untuk sektor logistik customer dibagi menjadi 2 segmen yaitu B2B (business to business) maupun B2C (business to customer) (Pramudita, 2019).

Salah satu perusahaan logistik di Indonesia yang menerapkan customer segmen B2B adalah PT XYZ Logistics. PT XYZ Logistics Indonesia merupakan perusahaan yang bergerak di bidang jasa freight forwarding dengan pelayanan khusus melayani jasa pengangkutan internasional. Pelayanan yang diberikan PT XYZ Logistics mendapatkan complain. Complain pelanggan biasanya terjadi akibat dokumen yang hilang, tidak lengkap, double dokumen, dokumen belum siap saat akan diambil, dan lamanya respon karyawan terhadap permintaan pelanggan. Adanya complain menunjukan penilaian customer terhadap terhadap kualitas pelayanan yang diberikan PT XYZ Logistics yang dapat berdampak pada penurunan jumlah customer. Customer merupakan aspek penting bagi perusahaan, karena customer berpengaruh pada perkembangan dan keberlansungan hidup perusahaan. Selain untuk memperoleh laba, perusahaan mengharapkan customer tetap loyal (Pramudita, 2020).

Penelitian ini bertujuan untuk mengetahui hubungan antara kualitas pelayanan dengan loyalitas pelanggan, kepuasan dengan loyalitas pelanggan, dan upaya apa yang harus dilakukan pihak PT XYZ Logistics dalam menjaga loyalitas pelanggannya.

\section{KAJIAN PUSTAKA} Service Quality

Service quality atau dalam Bahasa Indonesia disebut kualitas pelayanan adalah suatu keunggulan yang dimiliki perusahaan yang tidak berwujud. Kualitas layanan merupakan salah satu faktor penting yang dipertimbangkan 
oleh konsumen. Baik buruknya suatu kualitas layanan berhubungan dengan ekspektasi atau harapan dari konsumen pengguna jasanya. Oleh karena itu, kualitas suatu layanan perlu untuk dijaga secara konsisten dan selalu melakukan perbaikan yang terus menerus agar dapat menjaga, meningkatkan, serta memenuhi ekspektasi atau harapan pelanggan. .

Berdasarkan penelitian sebelumnya yang dikeluarkan oleh Zeithaml, Parasuraman \& Berry menyimpulkan lima dimensi untuk menjelaskan dan mengukur kualitas suatu layanan yang disebut dengan SERVQUAL. Dimensi yang diukur di dalam SERVQUAL adalah: (Zeithaml \& Berry, 1985)

1. Tangible adalah berwujud yaitu kemampuan perusahaan dalam menunjukkan fasilitas fisik sebagai pendukung layanan kepada konsumen.

2. Reliability adalah kehandalan yaitu dimensi yang mengukur kemampuan perusahaan untuk memberikan pelayanan sesuai dengan yang dijanjikan

3. Responsiveness adalah tanggap yaitu kemampuan layanan untuk membantu dan memberikan pelayanan yang cepat dan tepat dengan menyampaikan informasi yang jelas

4. Assuraince adalah jaminan dan kepastian yaitu kemampuan para pegawai perusahaan untuk menumbuhkan rasa percaya para pelanggan kepada perusahaan

5. Empathy adalah empati yaitu memberikan perhatian yang bersifat individual kepada para pelanggan (Sarjono \& Natalia, 2014).

\section{Kepuasan Pelanggan}

Kepuasan pelanggan menurut Kotler adalah perasaan senang atau kecewa pelanggan yang muncul setelah membandingkan antara ekspektasi dan realita terhadap suatu produk atau jasa (Kotler \& Keller, 2012). Kepuasan pelanggan merupakan ukuran performa suatu produk atau jasa yang dirasakan oleh pelanggan. Suatu produk atau layanan bisa dikatakan buruk apabila realita dari produk atau jasa yang dirasakan oleh pelanggan berada dibawah ekspektasi pelanggan. Begitupun sebaliknya, apabila suatu produk atau jasa dikatakan baik apabila realita dari produk atau jasa yang dirasakan oleh pelanggan melebihi ekspektasinya.

\section{Loyalitas Pelanggan}

Loyalitas pelanggan merupakan behaviour dari pelanggan yang bersifat psikologis dimana loyalitas berhubungan dengan keyakinan terhadap suatu produk atau layanan (Hasan, 2014). Selain terhadap produk atau layanan, loyalitas pelanggan juga merupakan sikap atau perilaku konsumen terhadap suatu merek (Hasan, 2014). Berdasarkan pengertian tersebut, loyalitas pelanggan dapat disimpulkan sebagai komitmen dari konsumen untuk terus loyal atau setia terhadap suatu produk atau layanan maupun juga merek yang ditunjukan dengan adanya pembelian berulang oleh pelanggan.

\section{METODE PENELITIAN}

Penelitian ini menggunakan metode deskriptif analisis dengan perhitungan menggunakan analisis regresi logistik ordinal. Regresi logistik ordinal merupakan salah satu analisis regresi yang digunakan untuk menganalisis hubungan antara variabel respon/terikat dengan variabel prediktor/bebas, dimana variabel respon bersifat polychotomous dengan skala ordinal. Populasi pada penelitian ini merupakan populasi tidak terhingga. Populasi diambil dari pelanggan yang menggunakan jasa $\mathrm{PT} \mathrm{XYZ}$ Logistics. Pengambilan sampel dalam penelitian ini adalah 10 kali operasional variable berdasarkan Roscoe (1975) dalam Amirullah (2015) yang berarti sampel yang digunakan sebanyak 70 responden (Amirullah, 2015).

\section{Teknik Pengumpulan Data}

\section{a. Observasi Lansung}

Observasi adalah teknik pengamatan dan pencatatan sistematis dari fenomenafenomena yang diselidiki. Peneliti melakukan pengamatan secara langsung mengenai kegiatan dan kondisi perusahaan di PT XYZ Logistics, dan peneliti mencatat beberapa informasi yang mendukung penyusunan skripsi ini sehingga peneliti memperoleh informasi dengan mengikuti proses yang terkait dengan penelitian ini.

\section{b. Kuesioner}

Teknik pengumpulan data yang digunakan oleh peneliti adalah dengan cara membagikan kuesioner kepada responden yaitu customer yang menjadi pelanggan di PT XYZ Logistics. Penyebaran kuesioner kepada customer dilakukan dengan cara memberikan kesempatan kepada responden 
untuk mengisi sendiri kuesioner yang didapat dari peneliti.

\section{c. Dokumentasi}

Dokumentasi adalah pengumpulan data melalui pencatatan dari dokumen atau arsip yang ada PT XYZ Logistics khususnya data yang berhubungan dengan masalah yang diteliti. Data tersebut adalah data complain pelanggan dan jumlah customer.

d. Studi Kepustakaan (Library Research)
Pada bagian studi kepustakaan, diperoleh data pelengkap untuk mendukung penelitian, yaitu data yang diperoleh dari luar perusahaan. Studi ini sebagai dasar bagi peneliti untuk memperoleh referensi yaitu mengenai teoriteori yang berkaitan dengan permasalahan yang ada, yang bersumber dari buku-buku literatur. Peneliti mengumpulkan data dengan cara mempelajari konsep dan teori dari berbagai sumber literatur yang berhubungan dan membantu memecahkan masalah yang sedang diteliti.

\section{HASIL DAN PEMBAHASAN}

Hasil

\section{a. Uji Validitas dan Reliabilitas}

Uji Validitas

Tabel 1 Hasil Uji Validitas

\begin{tabular}{|c|c|c|c|c|c|}
\hline Variabel & Dimensi & Indikator & Korelasi & $\begin{array}{c}\mathbf{r} \\
\text { tabel }\end{array}$ & Ket \\
\hline \multirow{15}{*}{$\begin{array}{l}\text { X1: Kualitas } \\
\text { Pelayanan }\end{array}$} & \multirow{4}{*}{ Reliability } & $\mathrm{X} 1.1$ & 0,495 & \multirow{4}{*}{0,235} & \multirow{4}{*}{ Valid } \\
\hline & & $\mathrm{X} 1.2$ & 0,369 & & \\
\hline & & $\mathrm{X} 1.3$ & 0,432 & & \\
\hline & & X1.4 & 0,389 & & \\
\hline & \multirow{3}{*}{ Responsiveness } & $\mathrm{X} 1.5$ & 0,356 & \multirow{3}{*}{0.235} & \multirow{3}{*}{ Valid } \\
\hline & & X1.6 & 0,265 & & \\
\hline & & $\mathrm{X} 1.7$ & 0,337 & & \\
\hline & \multirow{3}{*}{ Assurance } & $\mathrm{X} 1.8$ & 0,286 & \multirow{3}{*}{0,235} & \multirow{3}{*}{ Valid } \\
\hline & & X1.9 & 0,272 & & \\
\hline & & $\mathrm{X} 1.10$ & 0,27 & & \\
\hline & \multirow[t]{3}{*}{ Empathy } & $\mathrm{X} 1.11$ & 0,281 & \multirow[t]{3}{*}{0,235} & \multirow[t]{3}{*}{ Valid } \\
\hline & & $\mathrm{X} 1.12$ & 0,283 & & \\
\hline & & $\mathrm{X} 1.13$ & 0,248 & & \\
\hline & \multirow[t]{6}{*}{ Tangible } & $\mathrm{X} 1.14$ & 0,265 & \multirow[t]{3}{*}{0,235} & \multirow[t]{3}{*}{ Valid } \\
\hline & & $\mathrm{X} 1.15$ & 0,458 & & \\
\hline \multirow{4}{*}{$\begin{array}{c}\text { X2: Kepuasan } \\
\text { Pelanggan }\end{array}$} & & $\mathrm{X} 2.1$ & 0,279 & & \\
\hline & & $\mathrm{X} 2.2$ & 0,682 & \multirow{3}{*}{0,235} & \multirow{3}{*}{ Valid } \\
\hline & & $\mathrm{X} 2.3$ & 0,424 & & \\
\hline & & $\mathrm{X} 2.4$ & 0,478 & & \\
\hline $\begin{array}{l}\text { Y: Loyalitas } \\
\text { Pelanggan }\end{array}$ & & $\mathrm{Y}$ & 0,368 & 0,235 & Valid \\
\hline
\end{tabular}

Dari tabel 1 menunjukan uji validitas dari seluruh variable memiliki rhitung lebih besar dari rtabel yang dapat disimpulkan bahwa masing-masing pernyataan adalah valid dan adanya keterkaitan setiap pernyataan pada kuesioner.

\section{Uji Reabilitas}

Tabel 1 Hasil Uji Reabilias

\begin{tabular}{|c|c|}
\hline $\begin{array}{c}\text { Cronbach's } \\
\text { Alpha }\end{array}$ & N of Items \\
\hline 0.679 & 21 \\
\hline
\end{tabular}

Berdasarkan gambar 1 hasil dari uji reabilitas dikatakan handal karena berada diantara $>0,6-0,8$ (Hair et al 2010). 


\section{b. Uji Kebebasan Antar Variabel (Multikolinearitas)}

Tabel 2 Hasil Uji Multikolinearitas

\begin{tabular}{|c|c|c|c|c|c|c|c|c|}
\hline \multirow{2}{*}{\multicolumn{2}{|c|}{ Model }} & \multicolumn{2}{|c|}{$\begin{array}{c}\text { Unstandardized } \\
\text { Coefficients }\end{array}$} & \multirow{2}{*}{$\begin{array}{c}\begin{array}{c}\text { Standardized } \\
\text { Coefficients }\end{array} \\
\text { Beta } \\
\end{array}$} & \multirow[t]{2}{*}{$\mathbf{t}$} & \multirow[t]{2}{*}{ Sig. } & \multicolumn{2}{|c|}{$\begin{array}{c}\text { Collinearity } \\
\text { Statistics }\end{array}$} \\
\hline & & B & Std. Error & & & & Tolerance & VIF \\
\hline & (Constant) & 2.381 & 0.976 & & 2.441 & 0.018 & & \\
\hline & $\mathrm{X} 1.1$ & 0.080 & 0.108 & 0.111 & 0.745 & 0.46 & 0.604 & 1.656 \\
\hline & $\mathrm{X} 1.2$ & -0.098 & 0.108 & -0.119 & -0.903 & 0.371 & 0.766 & 1.306 \\
\hline & $\mathrm{X} 1.3$ & 0.135 & 0.095 & 0.192 & 1.424 & 0.161 & 0.739 & 1.354 \\
\hline & $\mathrm{X} 1.4$ & -0.109 & 0.115 & -0.133 & -0.949 & 0.347 & 0.684 & 1.462 \\
\hline & $X 1.5$ & 0.069 & 0.071 & 0.126 & 0.967 & 0.338 & 0.794 & 1.260 \\
\hline & X1.6 & 0.117 & 0.100 & 0.164 & 1.172 & 0.247 & 0.683 & 1.465 \\
\hline & X1.7 & 0.060 & 0.066 & 0.117 & 0.914 & 0.365 & 0.812 & 1.232 \\
\hline & $\mathrm{X} 1.8$ & 0.037 & 0.264 & 0.039 & 0.138 & 0.891 & 0.165 & 6.061 \\
\hline & X1.9 & 0.104 & 0.098 & 0.150 & 1.058 & 0.295 & 0.668 & 1.496 \\
\hline & $\mathrm{X} 1.10$ & -0.126 & 0.079 & -0.222 & -1.607 & 0.114 & 0.700 & 1.428 \\
\hline & $\mathrm{X} 1.11$ & 0.020 & 0.068 & 0.037 & 0.288 & 0.775 & 0.792 & 1.262 \\
\hline & $\mathrm{X} 1.12$ & 0.239 & 0.105 & 0.343 & 2.277 & 0.027 & 0.588 & 1.700 \\
\hline & $\mathrm{X} 1.13$ & -0.012 & 0.071 & -0.024 & -0.175 & 0.862 & 0.690 & 1.449 \\
\hline & $\mathrm{X} 1.14$ & 0.011 & 0.199 & 0.011 & 0.055 & 0.956 & 0.336 & 2.976 \\
\hline & $\mathrm{X} 1.15$ & 0.022 & 0.216 & 0.022 & 0.100 & 0.921 & 0.267 & 3.751 \\
\hline & $\mathrm{X} 2.1$ & -0.031 & 0.112 & -0.043 & -0.274 & 0.785 & 0.531 & 1.882 \\
\hline & X2.2 & 0.062 & 0.117 & 0.087 & 0.53 & 0.599 & 0.500 & 2.001 \\
\hline & $\mathrm{X} 2.3$ & 0.056 & 0.250 & 0.064 & 0.226 & 0.822 & 0.168 & 5.955 \\
\hline & X2.4 & -0.083 & 0.138 & -0.103 & -0.599 & 0.552 & 0.451 & 2.219 \\
\hline
\end{tabular}

Berdasarkan gambar 2 bahwa perhitung VIF $\leq 10$ dan nilai tolerance $\geq 0,1$ sehingga kesimpulannya adalah antar variabel bebas tidak ditemukan multikolinearitas.

\section{c. Model Regresi}

Persamaan regresi yang digunakan adalah

$$
\begin{aligned}
\pi_{1} & =\frac{\exp \left(3,872+0,245 X_{1.1} \ldots-0,075 X_{2.4}\right)}{1+\exp \left(3,872+0,245 X_{1.1} \ldots-0,075 X_{2.4}\right)} \\
\pi_{2} & =\frac{\exp \left(5,261+0,245 X_{1.1} \ldots-0,075 X_{2.4}\right)}{1+\exp \left(5,261+0,245 X_{1.1} \ldots-0,075 X_{2.4}\right)} \\
\pi_{3} & =\frac{\exp \left(9,078+0,245 X_{1.1} \ldots-0,075 X_{2.4}\right)}{1+\exp \left(9,078+0,245 X_{1.1} \ldots-0,075 X_{2.4}\right)}
\end{aligned}
$$

d. Uji Kebaikan Model (Goodness Fit) Goodness-of-Fit

\begin{tabular}{|l|r|r|r|}
\hline & Chi-Square & \multicolumn{1}{c|}{ df } & \multicolumn{1}{c|}{ Sig. } \\
\hline Pearson & 215.236 & 188 & .084 \\
Deviance & 105.843 & 188 & 1.000 \\
\hline
\end{tabular}

Gambar 3 Uji Kebaikan Model

Berdasarkan gambar 3 nilai uji deviance 0,084 lebih besar dari signiifikasi $\alpha=0,05$, yang dapat disimpulkan bahwa model logit layak untuk digunakan.

\section{e. Uji Keberatian Model}

Model Fitting Information

\begin{tabular}{|l|r|r|r|r|}
\hline Model & \multicolumn{1}{|c|}{$\begin{array}{c}-2 \text { Log } \\
\text { Likelihood }\end{array}$} & Chi-Square & \multicolumn{1}{c|}{ df } & Sig. \\
\hline Intercept Only & 136.310 & & & \\
Final & 105.843 & 30.466 & 19 & .046 \\
\hline
\end{tabular}

\section{Gambar 4 Uji Keberatian Model}

Berdasarkan gambar 4 diketahui nilai statistiknya $G$ adalah 30,466. Diketahui hasil -2 log likelihood model B (tanpa variable prediktor) sebesar 136,310 dan hasil -2 likelihood model A (dengan variable) sebesar 105,843. Kriteria ini mengambil taraf nyata $\alpha=0,05$ dari tabel chi kuadrat diperoleh $\mathrm{X}_{(0,05,70)}^{2}=90,531$ dari tabel maka $H_{0}$ ditolak jika $G(30,466)>X^{2}{ }_{(\alpha}$, v) $(90,531)$ dimana $v$ adalah banyaknya variabel prediktor. Dapat disimpulkan 
bahwa variable bebas berpengaruh terhadap variable terikat.

\section{f. Uji Wald}

Tabel 2 Hasil Uji Wald

\begin{tabular}{|c|c|c|c|c|}
\hline Variabel & Dimensi & Indikator & Wald & Sig \\
\hline \multirow{16}{*}{$\begin{array}{l}\text { X1: Kualitas } \\
\text { Pelayanan }\end{array}$} & \multirow{4}{*}{ Reliabillity } & $\mathrm{X} 1.1$ & 0,462 & 0,497 \\
\hline & & $\mathrm{X} 1.2$ & 1,214 & 0,271 \\
\hline & & $\mathrm{X} 1.3$ & 1,716 & 0,19 \\
\hline & & $\mathrm{X} 1.4$ & 0,863 & 0,353 \\
\hline & \multirow[t]{3}{*}{ Responsiveness } & $\mathrm{X} 1.5$ & 1,195 & 0,274 \\
\hline & & X1.6 & 1,56 & 0,212 \\
\hline & & $\mathrm{X} 1.7$ & 0,644 & 0,422 \\
\hline & \multirow[t]{3}{*}{ Assurance } & $\mathrm{X} 1.8$ & 0,085 & 0,77 \\
\hline & & X1.9 & 1,805 & 0,179 \\
\hline & & $\mathrm{X} 1.10$ & 3,119 & 0,077 \\
\hline & \multirow[t]{3}{*}{ Emphaty } & $\mathrm{X} 1.11$ & 0,697 & 0,404 \\
\hline & & $\mathrm{X} 1.12$ & 6,891 & 0,009 \\
\hline & & $\mathrm{X} 1.13$ & 0,605 & 0,437 \\
\hline & \multirow[t]{3}{*}{ Tangible } & $\mathrm{X} 1.14$ & 0,57 & 0,45 \\
\hline & & $\mathrm{X} 1.15$ & 0,319 & 0,572 \\
\hline & & X2.1 & 0,11 & 0,918 \\
\hline $\mathrm{X} 2$ : & & $\mathrm{X} 2.2$ & 0,953 & 0,329 \\
\hline Kepuasan & & $\mathrm{X} 2.3$ & 0,039 & 0,844 \\
\hline Pelanggan & & $\mathrm{X} 2.4$ & 0,031 & 0,861 \\
\hline
\end{tabular}

Berdasarkan hasil uji wald indikator yang mempengaruhi loyalitas pelanggan adalah $\mathrm{X} 1.12$, dikarenakan signifikasi $\alpha$ kurang dari 0,05 .

\section{g. Rasio Odd}

Indikator dengan signifikasi nyata dan berpengaruh pada loyalitas pelanggan adalah X1.12 dengan odds ratio $\Psi=\mathrm{e}^{0,981}=$

\section{Pembahasan}

Melanjuti dari hasil penelitian untuk meningkatkan loyalitas pelanggan PT XYZ

Logistics dapat membuat sistem informasi
2,7. Hal ini dapat diartikan bahwa peluang pelanggan akan menjadi loyal pada indikator X1.12 (memberikan informasi/penjelasan kepada setiap pelanggan yang membutuhkan) 2,7 kali dibanding dengan pelanggan yang tidak loyal.

dan pelatihan pegawai baik dilakukan salah satu ataupun keduanya. Berikut adalah hasil cost benefit analysis-nya:

\section{Pembuatan Sistem Informasi}

Tabel 3 Cost Benefit Analysis Sistem Informasi

\begin{tabular}{|c|c|c|}
\hline Keuntungan & & \\
\hline Re-print FCR & & Rp50.000.000 \\
\hline 24\% Reduce In Lost Customer & & Rp240.000.000 \\
\hline Total Benefit & & Rp290.000.000 \\
\hline \multicolumn{3}{|c|}{ Biaya Pembuatan Sistem Informasi } \\
\hline Procurement Cost & & Rp12.000.000 \\
\hline Biaya Konsultasi Pengadaan & Rp5.000.000 & \\
\hline Biaya Fasilitas Hardware & Rp7.000.000 & \\
\hline Start Up Cost & & Rp2.000.000 \\
\hline Biaya Instalaasi & Rp1.000.000 & \\
\hline
\end{tabular}



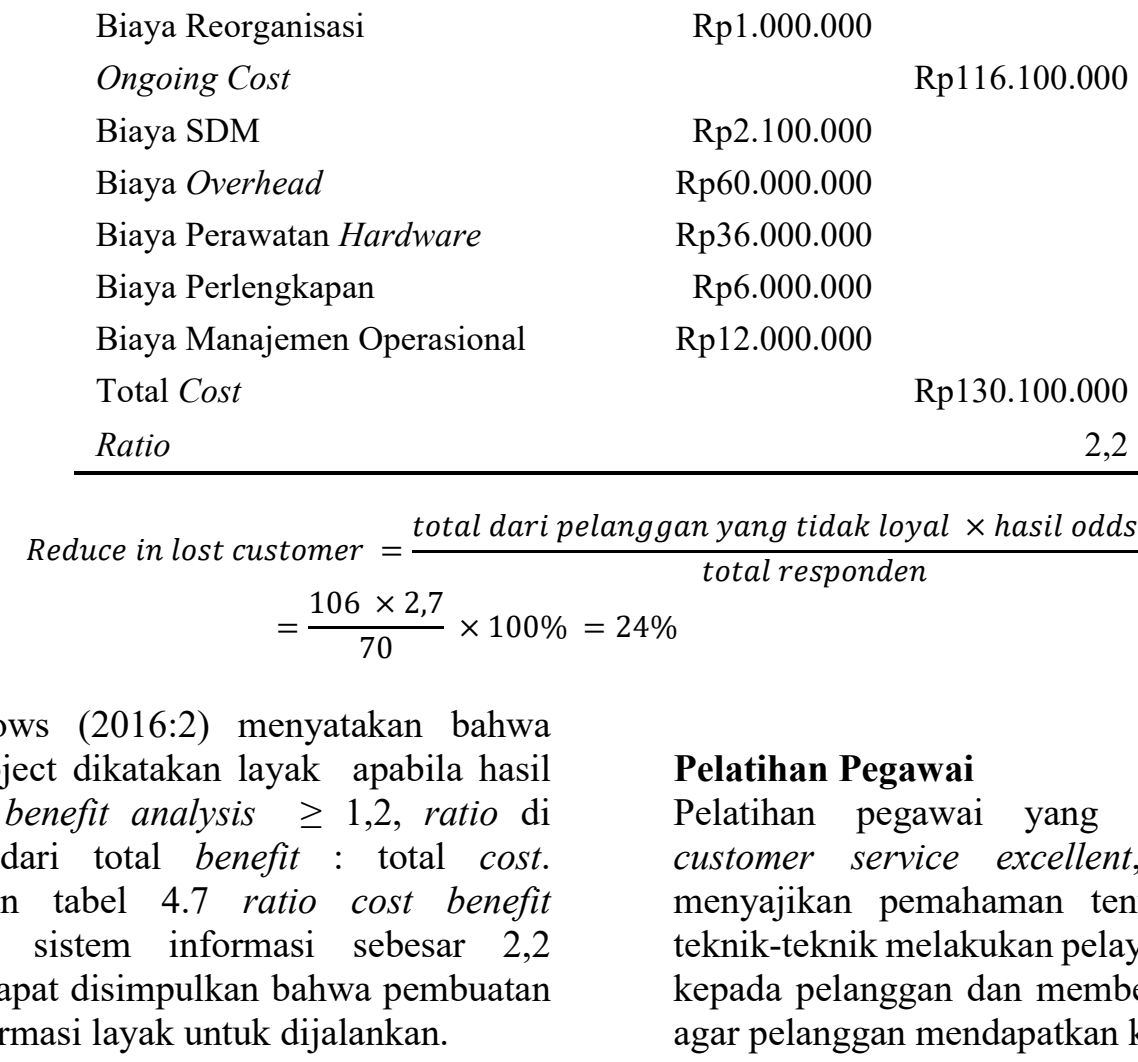

Dick Billows (2016:2) menyatakan bahwa sebuah project dikatakan layak apabila hasil ratio cost benefit analysis $\geq 1,2$, ratio $\mathrm{di}$ dapatkan dari total benefit : total cost. Berdasarkan tabel 4.7 ratio cost benefit pembuatan sistem informasi sebesar 2,2 sehingga dapat disimpulkan bahwa pembuatan sistem informasi layak untuk dijalankan.

\section{Pelatihan Pegawai}

Pelatihan pegawai yang diambil adalah customer service excellent, pelatihan ini menyajikan pemahaman tentang bagaimana teknik-teknik melakukan pelayanan yang prima kepada pelanggan dan memberikan pelayanan agar pelanggan mendapatkan kepuasan.

Tabel 4 Cost Benefit Analysis Pelatihan Pegawai

\begin{tabular}{|c|c|c|}
\hline Keuntungan & & \\
\hline Re-print FCR & & Rp50.000.000 \\
\hline $24 \%$ Reduce In Lost Customer & & $\mathrm{Rp} 240.000 .000$ \\
\hline Total Benefit & & Rp290.000.000 \\
\hline \multicolumn{3}{|l|}{ Biaya Pe latihan Pe gawai } \\
\hline Biaya Pelatihan Pegawai & Rp4.950.000 & Rp133.650.000 \\
\hline Biaya Transport & Rp150.000 & Rp4.050.000 \\
\hline Total Cost & & Rp137.700.000 \\
\hline Ratio & & 2,1 \\
\hline
\end{tabular}

Berdasarkan tabel 4 ratio cost benefit analysis pelatihan pegawai sebesar 2,1 sehingga dapat disimpulkan bahwa pelatihan pegawai dapat dilakukan.

\section{Pembuatan Sistem Informasi dan Pelatihan Pegawai}

Tabel 5 Cost Benefit Analysis Pembuatan Sistem Informasi dan Pelatihan Pegawai

\begin{tabular}{lr}
\hline Keuntungan & \\
\hline Re-print FCR & $\mathrm{Rp} 50.000 .000$ \\
$24 \%$ Reduce In Lost Customer & $\mathrm{Rp} 240.000 .000$ \\
Total Benefit & $\mathrm{Rp} 290.000 .000$ \\
\hline Biaya Pembuatan Sistem Informasi & \\
\hline Procurement Cost & $\mathrm{Rp} 12.000 .000$ \\
Biaya Konsultasi Pengadaan & $\mathrm{Rp} 5.000 .000$ \\
Biaya Fasilitas Hardware & $\mathrm{Rp} 7.000 .000$ \\
Start Up Cost & $\mathrm{Rp} 2.000 .000$
\end{tabular}




\begin{tabular}{|c|c|c|}
\hline Biaya Instalaasi & & Rp1.000.000 \\
\hline Biaya Reorganisasi & & Rp1.000.000 \\
\hline Ongoing Cost & & Rp116.100.000 \\
\hline Biaya SDM & & Rp2.100.000 \\
\hline Biaya Overhead & & Rp60.000.000 \\
\hline Biaya Perawatan Hardware & & Rp36.000.000 \\
\hline Biaya Perlengkapan & & Rp6.000.000 \\
\hline Biaya Manajemen Operasional & & Rp12.000.000 \\
\hline Total Cost Pembuatan Sistem Informasi & & Rp130.100.000 \\
\hline \multicolumn{3}{|l|}{ Biaya Pelatihan Pegawai } \\
\hline Biaya Pelatihan Pegawai & $\begin{array}{l}27 \mathrm{X} \mathrm{Rp} \\
4.950 .000\end{array}$ & Rp133.650.000 \\
\hline Biaya Transport & $\begin{array}{l}27 \times \mathrm{Rp} \\
150.000\end{array}$ & Rp4.050.000 \\
\hline Total Cost Pelatihan Pegawai & & Rp137.700.000 \\
\hline Total Cost & & Rp267.800.000 \\
\hline Ratio & & 1,08 \\
\hline
\end{tabular}

Berdasarkan tabel 5 ratio cost benefit analysis pembuatan sistem informasi dan pelatihan pegawai sebesar 1,08 sehingga dapat disimpulkan bahwa pembuatan sistem informasi dan pelatihan pegawai yang dilakukan beramaan tidak dapat dijalankan atau tidak layak karena ratio dibawah 1,2.

Berdasarkan hasil cost benefit analysis kegiatan atau proyek yang layak dilakukan adalah salah satu dari pembuatan system informasi atau pelatihan pegawai, namun yang paling layak untuk dilakukan adalah pembuatan sistem informasi.

\section{REFERENSI}

Amirullah. (2015). Pengantar Manajemen. Jakarta: Mitra Wacana Media.

Berita Satu. (2017). Volatilitas Logistik Indonesia Tertinggi di Asean. Berita Satu. Retrieved from https://www.beritasatu.com/ekonomi/430 959-volatilitas-logistik-indonesiatertinggi-di-asean.html

Hasan, A. (2014). Marketing dan Kasus-Kasus Pilihan. Yogyakarta: CAPS.

Kotler, P., \& Keller, K. L. (2012). Marketing Management (Global Edi). London: Pearson Education Limited 2012.

Pramudita, A. S. (2019). USULAN RUTE DISTRIBUSI SEBAGAI UPAYA MENCAPAI KEUNGGULAN
KOMPETITIF MELALUI EFISIENSI BIAYA TRANSPORTASI PT POS. Jurnal Logistik Bisnis, 09(2), 90-96. Retrieved from https://ejurnal.poltekpos.ac.id/index.php/l ogistik/article/view/570/408

Pramudita, A. S. (2020). Efisiensi Saluran Distribusi Area Pemasaran PT Nutrifood Indonesia di Pulau Jawa Menggunakan Data Envelopment Analysis. Coopetition: Jurnal Ilmiah Manajemen, X(1), 1-6. https://doi.org/https://doi.org/10.32670/c oopetition.v11i1.67

Pramudita, A. S., Yanuar, A., \& Hilman, T. (2019). BUSINESS MODEL FORMULATION FOR E-NEWSPAPER IN INDONESIA ( CASE STUDY: PIKIRAN RAKYAT ) FORMULASI MODEL BISNIS SURAT KABAR ELEKTRONIK DI INDONESIA ( STUDI KASUS : PIKIRAN RAKYAT ), 20(1), 15-31.

Sarjono, H., \& Natalia. (2014). SERVQUAL DALAM PELAYANAN KELAS PADA LABORATORIUM MANAJEMEN, 5(1), 404-417.

Zeithaml, V. A., \& Berry, L. L. (1985). A Conceptual Model of Service Quality and its Implication for Future Research ( SERVQUAL ), (September 2014). https://doi.org/10.2307/1251430 